\title{
Myeloid-derived suppressor cells enhance the expression of melanoma-associated antigen A4 in a Lewis lung cancer murine model
}

\author{
GUILAN SHI ${ }^{1}$, HUIRU WANG ${ }^{2}$ and XIUFEN ZHUANG ${ }^{3}$ \\ ${ }^{1}$ Department of Immunology, Zibo Vocational Institute, Zibo, Shandong 255314; ${ }^{2}$ Department of Immunology, \\ Cancer Institute, Peking Union Medical College and Chinese Academy of Medical Sciences, Beijing 100021; \\ ${ }^{3}$ Department of Oncology, Affiliated Hospital of Jiangsu University, Zhenjiang, Jiangsu 212000, P.R. China
}

Received September 1, 2014; Accepted June 3, 2015

DOI: $10.3892 / \mathrm{ol} .2015 .3918$

\begin{abstract}
The cancer-testis (CT) family of antigens are expressed in multiple types of malignant neoplasm and are silent in normal tissues, apart from the testis. Immunotherapy targeting CT antigens is a promising therapeutic strategy for treatment of solid tumors. One member of this family, melanoma-associated antigen A4 (MAGE-A4), has been demonstrated to be expressed in melanomas and lung cancer. Patients with tumors expressing the MAGE-A4 antigen exhibit specific cellular and humoral immune responses to the antigen, resulting in a favorable prognosis. Conversely, the expression of MAGE-A4 is associated with poor survival in lung cancer. Myeloid-derived suppressor cells (MDSCs) are a heterogeneous population of immunosuppressive cells, which are upregulated in the cancer microenvironment. Little is known regarding any potential correlation between the expression of MAGE-A4 antigens and the accumulation of MDSCs. The present study aimed to examine the association between circulating MDSC levels and MAGE-A4 expression in a mouse model of Lewis lung cancer. The expression of MAGE-A4 in tumor cells or tissues was evaluated using western blotting, while the percentage of MDSCs $\left(\mathrm{CD} 11 \mathrm{~b}^{+} \mathrm{Gr}-1^{+}\right)$in the blood was detected by flow cytometry. In addition, the suppressive capacity of MDSCs and the effectiveness of MDSC depletion were assessed in C57BL/6 tumor-bearing mice. MDSCs were demonstrated to upregulate MAGE-A4 expression via the phosphosphorylated-signal transducer and activator of transcription $3^{705}$ pathway, while depletion of MDSCs
\end{abstract}

Correspondence to: Dr Huiru Wang, Department of Immunology, Cancer Institute, Peking Union Medical College and Chinese Academy of Medical Sciences, 7 Pan Jia Yuan Nan Li, Chaoyang, Beijing 100021, P.R. China

E-mail: wanghuiruru@163.com

Key words: lung cancer, immunotherapy, melanoma-associated antigen A4, myeloid-derived suppressor cells, phosphorylated-signal transducer and activator of transcription $3^{705}$ decreased the tumor growth rate, prolonged median survival and enhanced the recognition of MAGE-A4 by $\mathrm{CD}^{+} \mathrm{T}$ cells. These findings indicated that immunotherapeutic strategies involving induction of cytotoxic T lymphocytes that target MAGE-A4, in combination with MDSC depletion, may be an effective approach to immunotherapy for cancer types with high expression of MAGE-A4.

\section{Introduction}

Lung cancer is the leading cause of cancer-associated mortality in China (1). Despite advances in diagnostic and therapeutic modalities against lung cancer, there has been little improvement in patient prognostic outcomes. A clinical study identified immunotherapy as a potentially favorable alternative approach to the treatment of lung cancer (2). A large number of tumor-associated antigens have been identified in various types of human cancer, including the cancer-testis (CT) antigens. CT antigens are of significant interest as they are expressed in a variety of malignant neoplasms, normal testis germ cells and the placenta, but not in other normal human tissues (3). Melanoma-associated antigen A4 (MAGE-A4) is a CT antigen that has been reported to be expressed in melanomas, germ cell tumors, certain sarcomas and lung cancer (4). Patients with MAGE-A4-expressing tumors are capable of exhibiting specific cellular and humoral immune responses to targeting MAGE-A4 (5). However, while an abundant infiltration of $\mathrm{CD}^{+} \mathrm{T}$ cells has frequently been reported to improve clinical outcomes (6), increased tumor MAGE-A4 expression is associated with poor survival in patients with lung cancer $(7,8)$. This likely results from the inhibition of tumor-specific immune responses in patients with cancer, and while a number of complex factors are implicated in this process (9), myeloid-derived suppressor cells (MDSCs) have a prominent role $(10,11)$. MDSCs are a heterogeneous group of pathologically activated immature myeloid cells and myeloid precursors that possess potent immunosuppressive activity (10-12). MDSCs have been identified in the peripheral blood, lymphoid tissue and tumor tissue in a number of experimental mouse models (13). Other studies have also demonstrated that MDSCs inhibit the effector 
function of T cells in tumor-bearing animals and patients with cancer $(14,15)$. The association between infiltration of $\mathrm{CD}^{+}$ T cells and increased tumor MAGE-A4 expression is not clear. Abundant infiltration of $\mathrm{CD}^{+} \mathrm{T}$ cells has frequently been reported to improve clinical outcomes. Clinical evidence also confirmed that MAGE-A4-expressing tumors are capable of exhibiting specific cellular and humoral immune responses to targeting MAGE-A4. However, increased tumor MAGE-A4 expression is associated with poor survival in patients with lung cancer (16).

Therefore, the present study aimed to identify the reason behind this association. The expression of MAGE-A4 was evaluated and the number of circulating MDSC were determined in a mouse model of Lewis lung cancer (LLC), to aid the elucidation of the association between MDSCs and MAGE-A4.

\section{Materials and methods}

Cell lines and animals. The LLC tumor cell line was purchased from the American Type Culture Collection (ATCC ${ }^{\circledR}$ CRL-1642 ${ }^{\mathrm{TM}}$; Manassas, VA, USA) and maintained in the Department of Immunology, Peking Union Medical College and Chinese Academy of Medical Sciences (Beijing, China). The B16F10 melanoma control cells were provided by Dr Lieping Chin (Department of Immunology, School of Medicine, Yale University, New Haven, CT, USA) (17). These murine tumor cells were maintained in Dulbecco's modified Eagle's medium/F12 medium containing 10\% heated-inactivated fetal calf serum (FCS), $2 \mathrm{mM}$ L-glutamine, $10 \mathrm{mM}$ HEPES, penicillin $(100 \mathrm{U} / \mathrm{ml})$-streptomycin $(50 \mu \mathrm{g} / \mathrm{ml})$ solution and $1 \%$ sodium pyruvate solution (Gibco Life Technologies, Carlsbad, CA, USA).

Female 6-8 week-old C57BL/6 mice $(n=20)$ were obtained from the Experimental Animal Institute of Peking Union Medical College. Mice were subjected to a $12 \mathrm{~h}$ light/dark cycle and maintained in a specific pathogen-free environment at $18-23^{\circ} \mathrm{C}$ with $40-60 \%$ humidity. Food and water were accessible at all times. All protocols involving animals used in the present study were approved by the Animal Research Ethics Committee of the Cancer Institute and Hospital, Peking Union Medical College and Chinese Academy of Medical Sciences (no. 20140002, Beijing, China).

In vivo depletion of MDSC. LLC tumor cells $\left(1 \times 10^{6}\right)$ were resuspended in $100 \mu 1$ phosphate-buffered saline (PBS) and subcutaneously inoculated into the right flanks of four C57BL/6 mice. These LLC tumor-bearing mice were enrolled in the study when the primary tumor reached $4-8 \mathrm{~mm}$ in diameter. The monoclonal antibody (mAb) Gr-1 (RB6-8C5; $200 \mu \mathrm{g}$ in $100 \mu \mathrm{l}$ PBS; BioLegend, Inc., San Diego, CA, USA) was intraperitoneally administered on days 5, 10 and 15 to deplete MDSCs. Control LLC tumor-bearing mice $(n=1)$ were treated with immunoglobulin $\mathrm{G}$ (rat $\mathrm{IgG}_{2 \mathrm{~b}}$; BioLegend, Inc.). Tumor dimensions were measured two or three times per week with digital calipers (Cangzhou Yongkang Medical Devices Co.,Ltd., Yongkang, China), and the tumor volume was calculated using the formula: Tumor volume $\left(\mathrm{mm}^{3}\right)=0.52 \mathrm{x}\left(\right.$ length $\mathrm{x}$ width $\left.{ }^{2}\right)$. Overall animal survival was monitored following conclusion of the treatment. Subsequently, mice were sacrificed 19 days after tumor cell inoculation, using carbon dioxide and tumor tissues were resected. A total of 5 mice were used per group, and all experiments were repeated twice. All experiments were conducted according to animal studies ethics committee guidelines.

Flow cytometric analysis. Cells from the bone marrow or spleen of LLC tumor-bearing mice were harvested 19 days after tumor cell inoculation, under sterile conditions. Single-cell suspensions were prepared, and red blood cells were removed using Tris lysis buffer (144 mM NH 4 Cl, $17 \mathrm{mM}$ Tris- $\mathrm{mCl}$; pH 7.2; Zhongshan Golden Bridge Biotechnology Co., Ltd., Beijing, China). Mononuclear cells isolated from the bone marrow or spleen were incubated at $4^{\circ} \mathrm{C}$ for 30 min with the following fluorescently conjugated rat $\mathrm{mAbs}$ purchased from BioLegend, Inc. [0.2 $\mu \mathrm{g}$ Abs per $10^{6}$ cells $\left.(100 \mu \mathrm{l})\right]$ : Anti-CD45 (allophycocyanin; 30-F11), anti-CD11b [fluorescein isothiocyanate (FITC); M1/70], anti-Gr-1 [phycoerythrin (PE), RB6-8C5], anti-CD8 (PE; 53-6.7) and anti-CD3 (PE/Cy7; 145-2C11). Subsequently, CD $45^{+} / \mathrm{CD} 11 b^{+} / \mathrm{Gr}-1^{+}$cells (MDSCs) or $\mathrm{CD} 45^{+} / \mathrm{CD}^{+} / \mathrm{CD}^{+}$cells were purified by cell sorting using a FACS Calibur (BD Biosciences, Franklin Lakes, NJ, USA) instrument to $>90 \%$ purity.

MDSC culture was performed as described previously with modifications (18). Briefly, sorted bone marrow populations $\left(\mathrm{CD}_{11 \mathrm{~b}} / \mathrm{Gr}-1^{+}\right.$and $\left.\mathrm{CD}^{+} / \mathrm{CD}^{+}\right)$were cultured in six-well plates $\left(1 \times 10^{5}\right.$ cells/well) for 3 days with the addition of recombinant mouse granulocyte-macrophage colony-stimulating factor (GM-CSF; $50 \mathrm{ng} / \mathrm{ml}$; R\&D Systems, Minneapolis, MN, USA), prior to harvesting the supernatant for use. $\mathrm{CD}^{+} \mathrm{T}$ cells obtained from the spleen were used as effector cells for a cytotoxic assay.

For surface staining, murine leukocytes from heparinized whole tail blood $(40 \mu \mathrm{l})$ collected on days 8 and 19 post-tumor challenge $(n=4)$ were incubated with the following antibodies: Anti-CD45, anti-CD11b, anti-Gr-1, anti-CD8, anti-CD4 and anti-CD3 (BioLegend, Inc.), at a concentration of $0.2 \mu \mathrm{g}$ Abs per $10^{6}$ cells $(100 \mu \mathrm{l})$ at $4^{\circ} \mathrm{C}$ for $30 \mathrm{~min}$, according to standard protocols (19). Subsequently, $500 \mu$ 1 OptiLyse ${ }^{\circledR}$ lysis solution (Beckman Coulter, Brea, CA, USA) was added to each tube and incubated at room temperature for $10 \mathrm{~min}$. Following washing with PBS, the samples were subjected to flow cytometric analysis. Additional analysis was performed using FlowJo software (version 7.6.5; Tree Star, Inc., Ashland, OR, USA).

Cell proliferation assay. LLC cells were incubated with $5 \mu \mathrm{M}$ 5,6-carboxyfluorescein diacetate succinimidyl ester (CFSE; Invitrogen Life Technologies, Carlsbad, CA, USA) at $37^{\circ} \mathrm{C}$ for $10 \mathrm{~min}$ in serum-free media, and then washed in RPMI-1640 media containing 10\% FCS (Gibco Life Technologies). CFSE-labeled cells were cultured in complete media with the addition of supernatant from MDSCs in 24-well plates ( $1 \mathrm{ml} /$ well, complete media and supernatant ratio, 1:1). Following $30 \mathrm{~h}$ of incubation at $37^{\circ} \mathrm{C}$ and $5 \% \mathrm{CO}_{2}$, the number of cell divisions undertaken by LLC cells was determined by flow cytometry.

Immunoblot analysis. Protein was extracted from LLC tumor tissues from C57BL/6 tumor-bearing mice, as well as LLC and B16F10 tumor cells, and analyzed by western blotting. Briefly, tumor tissues from C57BL/6 mice were flash-frozen in 
A

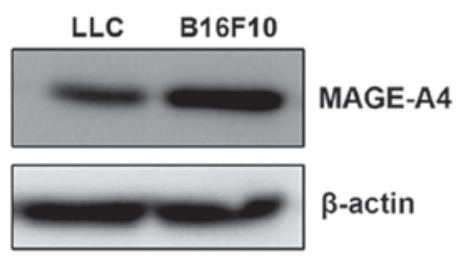

B

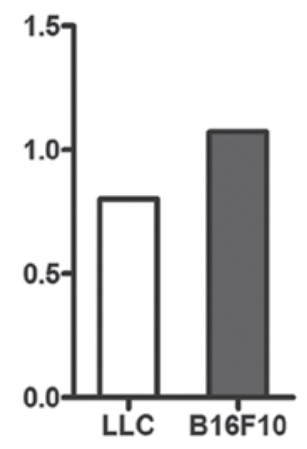

C

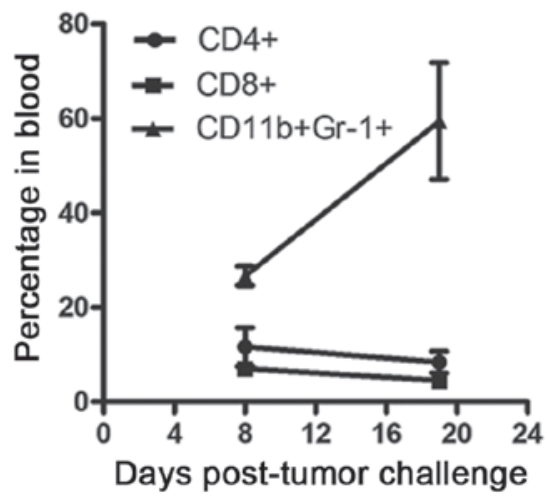

Figure 1. LLC tumor cells express the MAGE-A4 antigen and MDSCs accumulate with tumor development. (A) LLC and B16F10 tumor cells were harvested following culture and lysates were subjected to western blotting for MAGE-A4 antigen. $\beta$-actin was used as an internal control. (B) Quantification of western blot analysis indicates levels of MAGE-A4 expressed relative to $\beta$-actin. (C) Heparinized whole tail blood (40 $\mu 1)$ was collected on days 8 and 19 from tumor-bearing mice $(\mathrm{n}=4)$, and the percentage of MDSCs $\left(\mathrm{CD} 11 \mathrm{~b}^{+} \mathrm{Gr}-1^{+}\right)$was determined by flow cytometry. LLC, Lewis lung cancer; MAGE-A4, melanoma-associated antigen A4; MDSCs, myeloid-derived suppressor cells.

liquid nitrogen immediately following collection, while LLC or B16F10 tumor cells were harvested and washed with PBS. Ground tumor tissues and LLC or B16F10 cells were then lysed in pre-chilled radioimmunoprecipitation assay lysis buffer (Thermo Fisher Scientific, Waltham, MA, USA) containing protease and phosphatase inhibitor cocktails (Roche Diagnostics, New Providence, NJ, USA). Following centrifugation at $10,000 \mathrm{x} \mathrm{g}$ for $15 \mathrm{~min}$ at $4^{\circ} \mathrm{C}$, the supernatant was removed and protein concentration determined using Coomassie brilliant blue G-250 (Sigma-Aldrich, St. Louis, MO, USA). Total protein $(20 \mu \mathrm{g})$ was prepared for denaturing gel electrophoresis. For western blotting, proteins were separated on $12 \%$ SDS-PAGE gels (Bio-Rad Laboratories, Inc., Hercules, CA, USA) and transferred onto Immobilon-FL polyvinylidene difluoride membranes (EMD Millipore, Billerica, MA, USA) using a wet transfer apparatus (Bio-Rad Laboratories, Inc.). Following transfer, the blots were rinsed in washing buffer [Tris-buffered saline with Tween-20 (TBST): $20 \mathrm{mM}$ Tris base, $137 \mathrm{mM}$ $\mathrm{NaCl}, 0.1 \%$ Tween-20, pH 7.6] and blocked in blocking buffer (5\% non-fat dry milk in TBST; both from Bio-Rad Laboratories, Inc.) for $1 \mathrm{~h}$ at room temperature. Membranes were then washed in TBST and incubated with primary antibodies (1:1,000; Cell Signaling Technology, Inc., Danvers, MA, USA) diluted in TBST with $5 \%$ bovine serum albumin overnight at $4^{\circ} \mathrm{C}$. Subsequent washes in TBST were followed by incubation with secondary antibodies [goat anti-rabbit IgG-horseradish peroxidase (HRP), cat. no. 7074, or goat anti-mouse IgG-HRP, cat. no. 7076; 1:2,000; Cell Signaling Technology, Inc.] diluted in blocking buffer for $1 \mathrm{~h}$ at room temperature. Subsequently, the membranes were washed in TBST and the protein bands were visualized using an enhanced chemiluminescence western blotting system (GE Healthcare Life Sciences, Piscataway, NJ, USA). GAPDH and $\beta$-actin were used as internal controls for consistent protein loading. The following primary antibodies were used: Rabbit polyclonal MAGE-A4 antibody (AV54410), rabbit phosphorylated (p)-AKT ${ }^{473} \mathrm{XP}^{\circledR} \mathrm{mAb}$ (Ser473; D9E; 4060), rabbit total (t)-AKT mAb (pan ; C67E7; 4691), rabbit p-signal transducer and activator of transcription 3 (STAT3) ${ }^{705}$ $\mathrm{XP}^{\circledR}$ mAb (Tyr705; D3A7; 9145), rabbit p-STAT3 ${ }^{727} \mathrm{mAb}$ (Ser727; 9134), rabbit t-STAT3 mAb (79D7; 4904), mouse p-extracellular signal-regulated kinase (ERK)1/2 mAb [p44/42
MAPK (Erk1/2); Thr202/Tyr204; E10; 9106], rabbit t-ERK1/2 mAb [p44/42 MAPK (Erk1/2); 9102], mouse $\beta$-actin mAb (8H10D10; 12262) and rabbit GAPDH mAb (14C10; 2118). MAGE-A4 rabbit polyclonal antibody was purchased from Sigma-Aldrich, while all other primary antibodies mentioned above were obtained from Cell Signaling Technology, Inc. NuPAGE $^{\circledR}$ LDS Sample Buffer (NP0007), NuPAGE ${ }^{\circledR}$ MOPS SDS Running Buffer (NP0001-02) and Novex ${ }^{\circledR}$ Tris-Glycine Transfer Buffer (LC3675) for western blotting were purchased from Invitrogen Life Technologies. The intensities of bands on the membranes were determined using Quantity One software version 4.6.2 (Bio-Rad, Laboratories, Inc., Hercules, CA, USA).

Cytotoxicity assay. LLC tumor cells (target cells) were labeled with $5 \mu \mathrm{M} \mathrm{CFSE}$. Sorted CD8 ${ }^{+} \mathrm{T}$ cells were used as effector cells. Effector cells $\left(4 \times 10^{5}\right.$ cells/well) were cultured in 48-well plates with $2 \times 10^{4}$ labeled tumor target cells/well in $500 \mu \mathrm{l}$ RPMI-1640 containing $10 \%$ FCS. Following $4 \mathrm{~h}$ of incubation, propidium iodide (PI; $2 \mu \mathrm{g} / \mathrm{ml}$, Sigma-Aldrich) was added to identify killed target cells. Flow cytometric analysis identified $\mathrm{PI}^{+} \mathrm{CFSE}^{+}$cells (killed targets) and $\mathrm{PICFSE}^{+}$cells (viable targets). A total of $\sim 5,000$ target cells were acquired. The percentage of specific lysis was calculated in relation to the proportion of basal lysis in untreated cells using the following formula: Percentage of specific lysis $=$ proportion of lysis per sample - proportion of basal lysis / (1 - proportion of basal lysis) x 100.

Statistical analysis. GraphPad Prism V (GraphPad Software Inc., La Jolla, CA, USA) was used for statistical analyses. Data are presented as the mean \pm standard error of the mean, unless indicated otherwise. For comparisons between two groups, statistical analyses were performed using a Student's t-test, and $\mathrm{P}<0.05$ was considered to indicate a statistically significant difference. Survival curves were estimated using the Kaplan-Meier method, and differences among these were evaluated using the log-rank test.

\section{Results}

$M D S C$ s regulate the expression of MAGE-A4 via the p-STAT3 ${ }^{705}$ pathway. To establish a mouse model of lung 
A

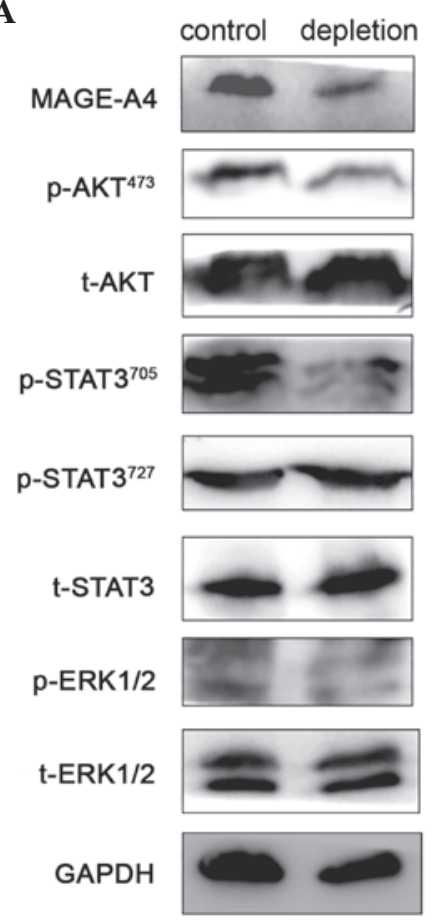

B

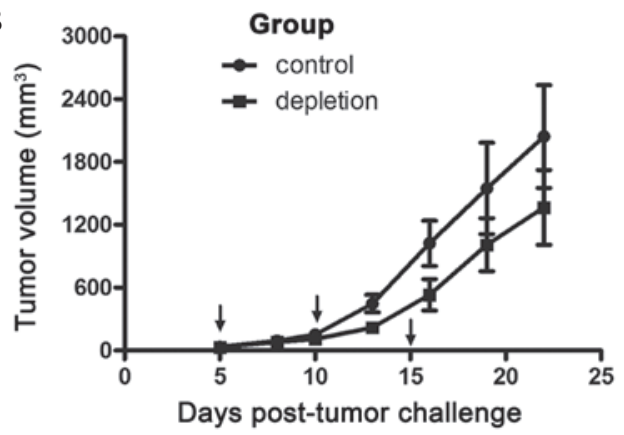

C

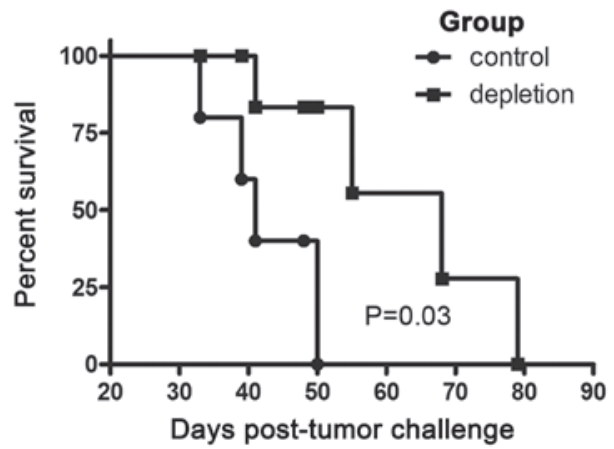

Figure 2. Depletion of MDSCs decreases MAGE-A4 expression and prolongs survival of tumor-bearing mice. (A) Protein was isolated from tumor tissues 19 days subsequent to tumor cell inoculation. MAGE-A4, p-AKT ${ }^{473}$, t-AKT, p-STAT3 ${ }^{705}$, p-STAT3727, t-STAT3, p-ERK1/2 and t-ERK1/2 levels in the tumor tissue were evaluated by western blotting. GAPDH levels served as an internal control. (B) LLC tumor cells (1x10 ${ }^{6}$ ) in $100 \mu 1$ phosphate-buffered saline were subcutaneously inoculated into the right flanks of C57BL/6 mice. Tumor growth curves compare subcutaneous tumor growth in the control and MDSC depletion groups, determined by caliper measurement. Arrows indicate the times of depletion assay. Values are expressed as the mean \pm standard error of the mean. (C) Kaplan-Meier estimate of overall survival, comparing control and MDSC depletion groups. There was a statistically significant difference between the two groups, $\mathrm{P}=0.03$. LLC, Lewis lung cancer; MAGE-A4, melanoma-associated antigen A4; MDSCs, myeloid-derived suppressor cells; p, phosphorylated; STAT3, signal transducer and activator of transcription 3; ERK, extracellular signal-regulated kinase; t, total

cancer , which highly expressed the CT antigen MAGE-A4, MAGE-A4 expression was first detected in LLC tumor cells. LLC tumor cells highly expressed the MAGE-A4 antigen, as did positive control B16F10 cells (Fig. 1A and B). Subsequently, the number of MDSCs present in the blood of tumor-bearing animals at various stages of tumor development was determined by flow cytometry, and an increased MDSC population was identified in advanced tumors (Fig. 1C).

To investigate the impact of MDSCs on MAGE-A4 expression, MDSCs were depleted in LLC tumor-bearing animals. Western blotting revealed that targeted depletion of MDSCs decreased MAGE-A4 expression in tumor-bearing mice. To elucidate the mechanism underlying how MDSCs enhanced MAGE-A4 expression in LLC tumor-bearing mice, p-AKT ${ }^{473}$, t-AKT, p-STAT3 ${ }^{705}$, p-STAT3 ${ }^{727}$, t-STAT3, p-ERK $1 / 2$ and t-ERK1/2 expression were evaluated by western blotting. The results presented in Fig. 2A revealed that depletion of MDSCs significantly inhibited MAGE-A4 expression, and that this effect was associated with the p-AKT ${ }^{473}$ and p-STAT3 ${ }^{705}$ pathways.

Depletion of MDSCs prolongs survival of mice bearing $L L C$ tumors. The survival of mice bearing LLC tumors following depletion of MDSCs was subsequently evaluated. Tumor masses did not generally decrease in size during the treatment period (Fig. 2B). However, depletion of $\mathrm{CD}_{11 \mathrm{~b}^{+} \mathrm{Gr} 1^{+} \text {cells }}$ conferred a significant survival advantage, with median survival of 68 days, whereas all control mice treated with control isotype IgG succumbed by day 50 (median survival, 41 days; Fig. 2C). Although this result may be interpreted as indicating a lack of efficacy, acute increases in tumor size following immune therapy have frequently been attributed to the recruitment and infiltration of immune cells, rather than the progressive growth of cancer cells (20).

Depletion of MDSCs enhances $C D 8^{+} T$ cell accumulation. Administration of the $\mathrm{mAb}$ Gr-1 markedly reduced the percentage and number of circulating MDSCs in LLC tumor-bearing C57BL/6 mice (Fig. 3A). The percentage of circulating $\mathrm{CD}^{+} \mathrm{T}$ cells increased $\sim 2$-fold $(13.11 \pm 2.59$ in control mice vs. $23.5 \pm 1.3$ in RB6-8C5-treated mice; $n=4$ per group; $\mathrm{P}=0.053$; Fig. $3 \mathrm{~B}$ ); however, this result was not statistically significant. Consistent with this trend, the percentage of circulating $\mathrm{CD}^{+} \mathrm{T}$ cells (Fig. 3C) in RB6-8C5-treated mice increased $\sim 2$-fold when compared with that of untreated mice, and this result was statistically significant $(7.63 \pm 1.23$ in control mice vs. $17.15 \pm 1.25$ in RB6-8C5-treated mice; $n=4$ per group; $\mathrm{P}=0.032$ ).

MDSCs suppress the cytotoxic activity of $C D 8^{+} T$ cells. To evaluate the effect of MDSCs on the efficacy of the cytotoxic immune response in the LLC animal model, $\mathrm{CD}^{+} \mathrm{T}$ cell cytotoxic activity was assessed by flow cytometry. CD8 ${ }^{+}$ T cell cytotoxicity towards LLC cells was found to be higher in the MDSC depletion group than that of the control group 
A

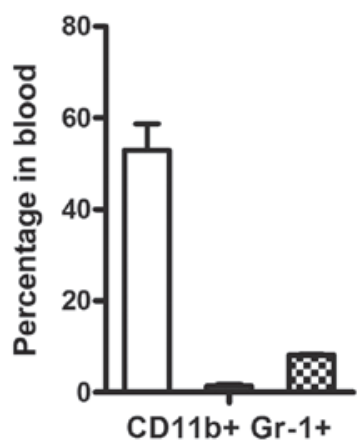

B

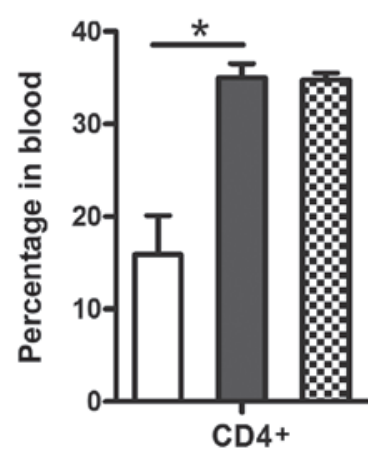

C

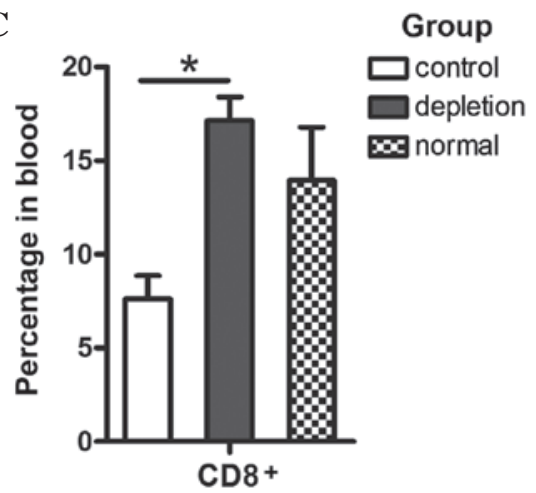

Figure 3. Systemic administration of RB6-8C5 antibody specifically depletes MDSCs in LLC tumor-bearing mice, and increases the number of circulating $\mathrm{CD}^{+}$and CD8 ${ }^{+} \mathrm{T}$ cells. (A) Heparinized whole tail blood $(40 \mu \mathrm{l})$ was collected from tumor-bearing mice (n=4) treated with or without the Gr-1 monoclonal antibody (RB6-8C5) on day 19, and the percentage of MDSCs (CD11b $\left.{ }^{+} \mathrm{Gr}-1^{+}\right)$in the blood was detected by flow cytometry. (B) Percentage of CD4 $4^{+}$cells in naïve, control and MDSC-depleted LLC tumor-bearing mice was quantified by flow cytometry. (C) Percentage of CD8 ${ }^{+} \mathrm{T}$ cells was quantified in naive, control and RB6-8C5-treated mice. Bar graphs indicate the percentage of MDSCs, CD4 ${ }^{+}$and CD8 ${ }^{+}$T cells in naïve, control and depletion groups. Data are presented as the mean \pm standard error of the mean from four independently treated animals. LLC, Lewis lung cancer; MDSCs, myeloid-derived suppressor cells. ${ }^{*}<0.05$.

A

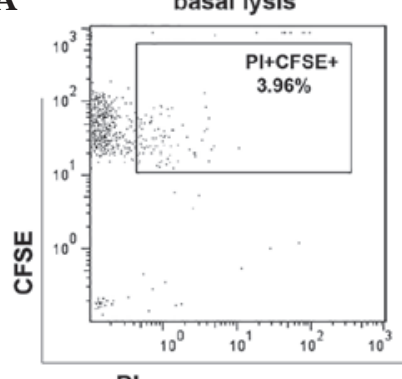

control

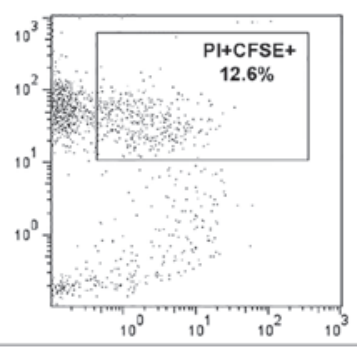

depletion

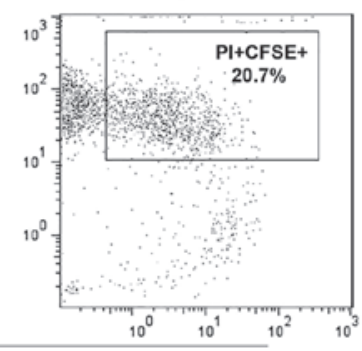

B

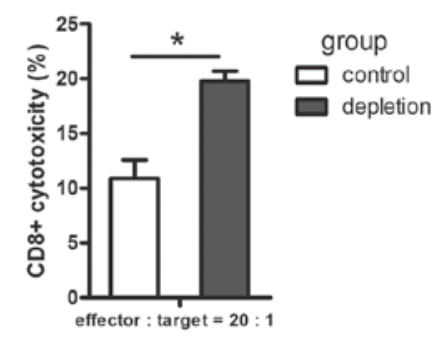

Figure 4. Targeted depletion of MDSCs promotes $\mathrm{CD}^{+} \mathrm{T}$ cell cytotoxic activity. (A) Cytotoxic activity was measured by FACS detection of CFSE ${ }^{+} \mathrm{I}^{+}$cells. Effector cells $\left(\mathrm{CD} 8^{+} \mathrm{T}\right.$ cells) were derived from the spleen $\left(4 \times 10^{5}\right)$. Cytotoxicity was determined by co-culturing effector cells with CFSE-labeled Lewis lung cancer target cells $\left(2 \times 10^{4}\right)$ in 48 -well plates for $4 \mathrm{~h}$. Target cell killing was analyzed on the basis of PI uptake by flow cytometry. (B) Bar graph quantifies the percentage of $\mathrm{PI}^{+} \mathrm{CFSE}^{+}$target cells in the control and depletion groups. ${ }^{*} \mathrm{P}<0.05$. Quantitative data are represented as the mean \pm standard error of the mean from one of two independent experiments ( $\mathrm{n}=4$ mice per treatment group). CFSE, 5,6-carboxyfluorescein diacetate succinimidyl ester; PI, propidium iodide; MDSCs, myeloid-derived suppressor cells.

(Fig. 4A and B). This confirmed that MDSC depletion in tumor-bearing mice resulted in functional activation of $\mathrm{CD}^{+}$ $\mathrm{T}$ cells, which, in combination with other factors, results in tumor regression.

These results demonstrated that cancer-conditioned MDSCs may impede the recognition of tumor antigens by $\mathrm{CD}^{+} \mathrm{T}$ cells and impair effector $\mathrm{T}$ cell activity in tumor-bearing mice. Furthermore, targeted depletion of MDSCs with Gr-1 therapy may enhance the endogenous anti-tumor immune response.

MDSC culture supernatant promotes proliferation of LLC tumor cells and enhances MAGE-A4 expression. The correlation between MAGE-A4 antigen expression and MDSC infiltration was further assessed by incubating LLC tumor cells with MDSC supernatant. MDSC supernatant significantly enhanced LLC cell proliferation (Fig. 5A and B; $\mathrm{P}=0.011$ ) and MAGE-A4 expression (Fig. 5C and D).

\section{Discussion}

The present study aimed to address the integrated association between MAGE-A4 expression, MDSC accumulation and clinicopathological characteristics including overall survival, as well as circulating $\mathrm{CD}^{+}$and $\mathrm{CD}^{+} \mathrm{T}$ cell levels in LLC tumor-bearing C57BL/6 mice. MAGE-A4 was selected for investigation due to its potential to elicit marked immune reactions (21). MAGE-A4 is a member of the CT antigen family and is not expressed in normal tissues, other than the testis and placenta. Additionally, high levels of MAGE-A4 expression are detected in lung cancer (22). This suggests that MAGE-A4 may be an optimal therapeutic target candidate, and the generation of an immune response to MAGE-A4 has previously been investigated (23). In addition, tumor-specific cytotoxic T lymphocytes (CTLs) recognizing MAGE gene products have been reported, and a large number of CTL epitopes within MAGE proteins have been identified (3,24-26). Furthermore, CTL epitopes within MAGE-A4 have been found to be presented by MHC class I (27-29), and an intensive accumulation of CD8 ${ }^{+} \mathrm{T}$ cells in the tumor nest has been reported to be correlated with favorable patient prognosis in numerous types of tumor (30-32). Theoretically, high expression levels of MAGE-A4 antigen should induce CTLs to infiltrate the tumor site and result in a favorable prognosis. However, in the present study, MAGE-A4 expression was associated with poor survival in tumor-bearing mice. A 
A

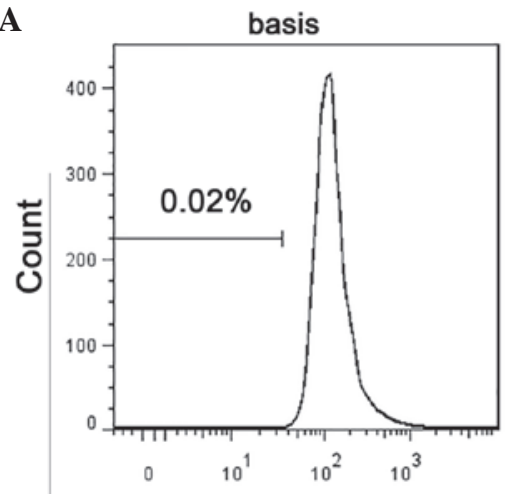
CFSE
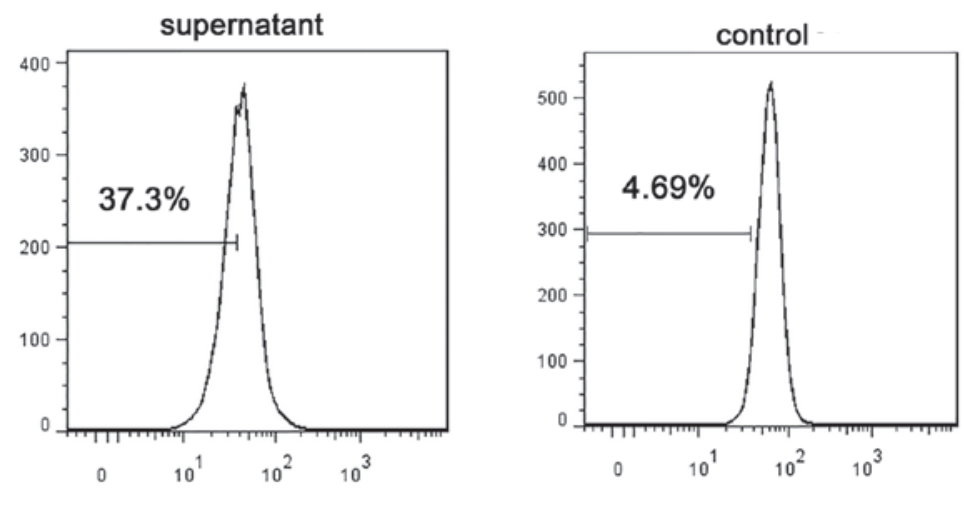

B

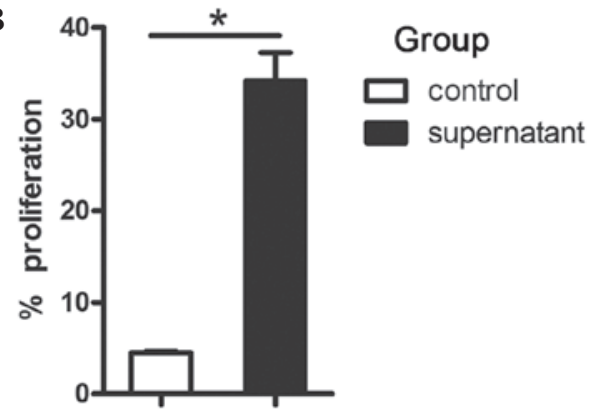

C

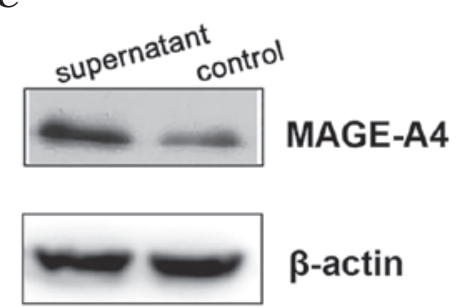

D

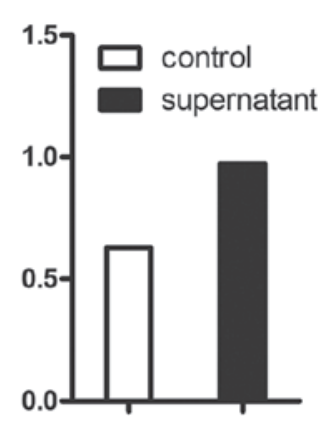

Figure 5. MDSC supernatant promotes LLC proliferation and enhances MAGE-A4 antigen expression. (A and B) Bone marrow-derived MDSCs were cultured for 3 days and then the supernatants were harvested. Subsequently, CFSE-labeled LLC cells were cultured in 24-well plates in complete media with MDSC supernatant at a 1:1 ratio. Percentages of LLC tumor cells which had undergone one or more cell divisions $30 \mathrm{~h}$ following culture are indicated. (C and D) Thirty hours following culture, LLC tumor cells were harvested, and MAGE-A4 levels were evaluated by western blotting. $\beta$-actin was used as an internal control. ${ }^{*} \mathrm{P}<0.05$. LLC, Lewis lung cancer; MAGE-A4, melanoma-associated antigen A4; MDSCs, myeloid-derived suppressor cells; CFSE, 5,6-carboxyfluorescein diacetate succinimidyl ester.

similar inverse correlation between MAGE-A4 expression and patient survival has been previously reported $(2,3,33,34)$. The precise reasons underlying why higher expression of MAGE-A4 does not improve patient prognosis have remained elusive. However, investigation of the accumulation of MDSCs in tumor-bearing individuals may aid the elucidation of the mechanisms underlying this effect. To the best of our knowledge, the present study was the first to report that depletion of a single immunosuppressive myeloid cell subset $\left(\mathrm{CD} 11 \mathrm{~b}^{+} \mathrm{Gr}-1^{+}\right)$reduces MAGE-A4 antigen expression via the p-AKT and p-STAT ${ }^{705}$ pathways, and induces endogenous $\mathrm{CD}^{+}$and $\mathrm{CD}^{+} \mathrm{T}$ cell accumulation in LLC tumor-bearing mice.

The term 'cancer' implies at least a certain degree of failure of immunity. Since tumors are self-derived, they benefit from multiple mechanisms of self-tolerance, including immune evasion (35). Neoplastic cells have additional elaborate mechanisms to subvert antitumor $\mathrm{T}$ cell activity, for example the induction of host immunosuppressive cells, including MDSCs and regulatory $\mathrm{T}$ cells, and MDSCs have been identified in a variety of human malignancies (36). Immunosuppression is not limited to the tumor microenvironment, and circulating myeloid cells capable of inducing dysfunctional immune responses have been repeatedly described $(37,38)$. Therefore, the levels of circulating MDSCs were evaluated, to determine their effect on MAGE-A4 expression. It was demonstrated that MAGE-A4 expression was upregulated with tumor development, and downregulated with depletion of MDSCs in LLC tumor-bearing mice. However, no direct association was identified between MDSCs and carcinogenesis or other molecules that affect the expression of MAGE-A4 in LLC tumor-bearing mice.

The number of MDSCs in the circulation exhibited an exclusive association with MAGE-A4 expression, and may also be correlated with prognosis. Evidence supporting a role for MDSCs in modulating MAGE-A4 expression is provided by the results of the assessment of LLC tumor cell proliferation, which demonstrated that MDSC supernatant was able to promote the growth of tumor cells and induce increased expression of MAGE-A4. MDSCs secrete multiple factors that may support the growth and survival of tumor cells (39-42), and it would be of interest to confirm whether MDSCs secrete soluble factors that regulate MAGE-A4 expression. In further support of this, it has previously been reported that CT antigen expression is association with cell cycle progression and proliferation (43-45), apoptosis (13) and susceptibility of cancer cells to cytokines (46), suggesting that the CT antigen itself may be associated with prognosis.

It is possible that a therapeutic strategy whereby CTLs targeting MAGE-A4 antigens may improve patient outcome (30). However, the present results demonstrated that the survival of tumor-bearing mice was prolonged following depletion of MDSCs, and the subsequent decrease in MAGE-A4 expression. Therefore, delineation of the mechanisms underlying MDSC expansion and enhanced MAGE-A4 expression in cancer represents an area of significant potential. A number of mechanisms 
may be exploited to disrupt the immunosuppressive capabilities of MDSCs, including impairing their trafficking to tumors, preventing accumulation, limiting immune cell activation (47) or inhibiting their recognition of tumor-associated antigens, including MAGE-A4. The present results demonstrated that the endogenous immune response does not have the capacity to recognize MAGE-A4 antigens, and that the MDSCs represent a critical barrier to eliciting such immune activity.

The present study indicated that depletion of MDSCs resulted in decreased expression of MAGE-A4, and that the induction of specific CTLs targeting MAGE-A4 decreased. Given that MAGE-A4 expression is regulated by MDSCs via the p-STAT3 ${ }^{705}$ pathway, it is possible that targeted depletion of MDSCs, while simultaneously enhancing the expression of MAGE-A4 via activation of the p-STAT3 ${ }^{705}$ pathway, may provide the opportunity to induce an activated $\mathrm{CD} 8^{+} \mathrm{T}$ cell response. Therefore, combining $\mathrm{CT}$ antigen therapy with targeted disruption of MDSCs and additional immune-based strategies may help to harness the full potential of the immune system to recognize and eradicate malignancies.

It is also possible that other cells and cytokines in the LLC environment, for example regulatory T cells and interleukin-6 or transforming growth factor- $\beta$ (which may be induced by MDSCs), may also contribute to the enhanced expression of MAGE-A4 identified in LLC (22). Further studies are required to elucidate the direct and indirect regulation of MAGE-A4 expression by MDSCs.

An ideal immunotherapeutic strategy for lung cancer would maximize the therapeutic index by improving antitumor effector immune cell functions, while inhibiting immune suppressor cells. The poor prognosis associated with MAGE-A4-expressing tumors highlights the need for the development of an aggressive therapy for their treatment. On the other hand, thesignificant correlation between MAGE-A4 expression and MDSC accumulation observed in the present study suggests that the spontaneous immune response may be incapable of overcoming their immunosuppressive state to eradicate the established tumor. These findings therefore indicate a novel mechanism of immunosuppression in the tumor microenvironment and provide a clear rationale for targeting MDSCs to enhance immune-based treatment or endogenous immune recognition of cancer.

In conclusion, to the best of our knowledge, the present study provides the first report of an association between MAGE-A4 and MDSCs. The data revealed that MDSCs present within the tumor may function as immunoregulators, which modulate cell signaling pathways in the tumor microenvironment. Additionally, the results demonstrated a critical role for the p-STAT3 ${ }^{705}$ pathway as a key mediator of immune suppressor cell differentiation (48) and LLC survival. Therefore, immunotherapeutic strategies involving induction of CTLs to target MAGE-A4, in combination with MDSC depletion, may provide an effective approach to cancer immunotherapy.

\section{Acknowledgements}

The present study is a project of the Shandong Province Higher Educational Science and Technology Program (no. J13LK58) and was supported in part by a Grant-in-Aid from the Zibo Vocational Institute (no. 2013VC01).

\section{References}

1. Zhi X: The Sixth South-North forum of lung cancer in China was held in CPPCC auditorium. Zhongguo Fei Ai Za Zhi 16: 661-662, 2013 (In Chinese).

2. Shigematsu Y, Hanagiri T, Shiota H, Kuroda K, Baba T, Mizukami M, So T, Ichiki Y, Yasuda M, So T, et al: Clinical significance of cancer/testis antigens expression in patients with non-small cell lung cancer. Lung Cancer 68: 105-110, 2010.

3. Coulie PG, Karanikas V, Lurquin C, Colau D, Connerotte T, Hanagiri T, Van Pel A, Lucas S, Godelaine D, Lonchay C, et al: Cytolytic T-cell responses of cancer patients vaccinated with a MAGE antigen. Immunol Rev 188: 33-42, 2002.

4. Baba T, Shiota H, Kuroda K, Shigematsu Y, Ichiki Y, Uramoto H, Hanagiri $\mathrm{T}$ and Tanaka F: Clinical significance of human leukocyte antigen loss and melanoma-associated antigen 4 expression in smokers of non-small cell lung cancer patients. Int J Clin Oncol 18: 997-1004, 2013.

5. Dhodapkar MV, Osman K, Teruya-Feldstein J, Filippa D, Hedvat CV, Iversen K, Kolb D, Geller MD, Hassoun H, Kewalramani T, et al: Expression of cancer/testis (CT) antigens MAGE-A1, MAGE-A3, MAGE-A4, CT-7 and NY-ESO-1 in malignant gammopathies is heterogeneous and correlates with site, stage and risk status of disease. Cancer Immun 3: 9, 2003.

6. Bolli M, Kocher T, Adamina M, Guller U, Dalquen P, Haas P, Mirlacher M, Gambazzi F, Harder F, Heberer M, et al: Tissue microarray evaluation of melanoma antigen $\mathrm{E}$ (MAGE) tumor-associated antigen expression: Potential indications for specific immunotherapy and prognostic relevance in squamous cell lung carcinoma. Ann Surg 236: 785-793, 2002.

7. Yakirevich E, Sabo E, Lavie O, Mazareb S, Spagnoli GC and Resnick MB: Expression of the MAGE-A4 and NY-ESO-1 cancer-testis antigens in serous ovarian neoplasms. Clin Cancer Res 9: 6453-6460, 2003.

8. Yoshida N, Abe H, Ohkuri T, Wakita D, Sato M, Noguchi D, Miyamoto M, Morikawa T, Kondo S, Ikeda H, et al: Expression of the MAGE-A4 and NY-ESO-1 cancer-testis antigens and $\mathrm{T}$ cell infiltration in non-small cell lung carcinoma and their prognostic significance. Int J Oncol 28: 1089-1098, 2006.

9. Zou W and Chen L: Inhibitory B7-family molecules in the tumour microenvironment. Nat Rev Immunol 8: 467-477, 2008.

10. Ostrand-Rosenberg S and Sinha P: Myeloid-derived suppressor cells: Linking inflammation and cancer. J Immunol 182: 4499-4506, 2009.

11. Gabrilovich DI and Nagaraj S: Myeloid-derived suppressor cells as regulators of the immune system. Nat Rev Immunol 9: 162-174, 2009.

12. Gabrilovich DI, Ostrand-Rosenberg S and Bronte V: Coordinated regulation of myeloid cells by tumours. Nat Rev Immunol 12: 253-268, 2012.

13. Marcar L, Maclaine NJ, Hupp TR and Meek DW: Mage-A cancer/testis antigens inhibit p53 function by blocking its interaction with chromatin. Cancer Res 70: 10362-10370, 2010.

14. Srivastava MK, Zhu L, Harris-White M, Huang M, St John M, Lee JM, Salgia R, Cameron RB, Strieter R, Dubinett S, et al: Targeting myeloid-derived suppressor cells augments antitumor activity against lung cancer. Immunotargets Ther 2012: 7-12, 2012.

15. Srivastava MK, Zhu L, Harris-White M, Kar UK, Huang M, Johnson MF, Lee JM, Elashoff D, Strieter R, Dubinett S, Sharma S, et al: Myeloid suppressor cell depletion augments antitumor activity in lung cancer. PLoS One 7: e40677, 2012.

16. Groeper C, Gambazzi F, Zajac P, Bubendorf L, Adamina M, Rosenthal R, Zerkowski HR, Heberer M and Spagnoli GC: Cancer/testis antigen expression and specific cytotoxic $\mathrm{T}$ lymphocyte responses in non small cell lung cancer. Int $\mathrm{J}$ Cancer 120: 337-343, 2007.

17. Cui NP, Xie SJ, Han JS, Ma ZF, Chen BP and Cai JH: Effective adoptive transfer of haploidentical tumor-specific $\mathrm{T}$ cells in B16-melanoma bearing mice. Chin Med J (Engl) 125: 794-800, 2012.

18. Morales JK, Kmieciak M, Knutson KL, Bear HD and Manjili MH: GM-CSF is one of the main breast tumor-derived soluble factors involved in the differentiation of CD11b-Gr1bone marrow progenitor cells into myeloid-derived suppressor cells. Breast Cancer Res Treat 123: 39-49, 2010.

19. Baumgartner CK, Ferrante A, Nagaoka M, Gorski J and Malherbe LP: Peptide-MHC class II complex stability governs CD4 T cell clonal selection. J Immunol 84: 573-581, 2010. 
20. Wolchok JD, Hoos A, O'Day S, Weber JS, Hamid O, Lebbé C, Maio M, Binder M, Bohnsack O, Nichol G, et al: Guidelines for the evaluation of immune therapy activity in solid tumors: Immune-related response criteria. Clin Cancer Res 15: 7412-7420, 2009.

21. Daudi S, Eng KH, Mhawech-Fauceglia P, Morrison C, Miliotto A, Beck A, Matsuzaki J, Tsuji T, Groman A, Gnjatic S: Expression and immune responses to MAGE antigens predict survival in epithelial ovarian cancer. PLoS One 9: e104099, 2014.

22. Chaux P, Luiten R, Demotte N, Vantomme V, Stroobant V, Traversari C, Russo V, Schultz E, Cornelis GR, Boon T, et al: Identification of five MAGE-A1 epitopes recognized by cytolytic T lymphocytes obtained by in vitro stimulation with dendritic cells transduced with MAGE-A1. J Immunol 163: 2928-2936, 1999.

23. Gunda V, Cogdill AP, Bernasconi MJ, Wargo JA and Parangi S: Potential role of 5-aza-2'-deoxycytidine induced MAGE-A4 expression in immunotherapy for anaplastic thyroid cancer. Surgery 154: 1456-1462,2013.

24. Ortiz ML, Lu L, Ramachandran I and Gabrilovich DI: Myeloid-derived suppressor cells in the development of lung cancer. Cancer Immunol Res 2: 50-58, 2014.

25. Nagorsen D, Scheibenbogen C, Marincola FM, Letsch A and Keilholz U: Natural T cell immunity against cancer. Clin Cancer Res 9: 4296-4303, 2003

26. Cuenca AG, Cuenca AL, Winfield RD, Joiner DN, Gentile L, Delano MJ, Kelly-Scumpia KM, Scumpia PO, Matheny MK, Scarpace PJ, et al: Novel role for tumor-induced expansion of myeloid-derived cells in cancer cachexia. J Immunol 192: 6111-6119, 2014.

27. Duffour MT, Chaux P, Lurquin C, Cornelis G, Boon T and van der Bruggen P: A MAGE-A4 peptide presented by HLA-A2 is recognized by cytolytic T lymphocytes. Eur J Immunol 29 : 3329-3337, 1999.

28. Kobayashi T, Lonchay C, Colau D, Demotte N, Boon T and van der Bruggen P: New MAGE-4 antigenic peptide recognized by cytolytic T lymphocytes on HLA-A1 tumor cells. Tissue Antigens 62: 426-432, 2003.

29. Zhang Y, Stroobant V, Russo V, Boon T and van der Bruggen P: A MAGE-A4 peptide presented by HLA-B37 is recognized on human tumors by cytolytic T lymphocytes. Tissue Antigens 60: 365-371, 2002.

30. Scanlan MJ, Altorki NK, Gure AO, Williamson B, Jungbluth A, Chen YT and Old LJ: Expression of cancer-testis antigens in lung cancer: Definition of bromodomain testis-specific gene (BRDT) as a new CT gene, CT9. Cancer Lett 150: 155-164, 2000.

31. Schumacher K, Haensch W, Röefzaad C and Schlag PM: Prognostic significance of activated CD8 (+) T cell infiltrations within esophageal carcinomas. Cancer Res 61: 3932-3936, 2001.

32. Cruz CR, Gerdemann U, Leen AM, Shafer JA, Ku S, Tzou B, Horton TM, Sheehan A, Copeland A, Younes A, et al: Improving T-cell therapy for relapsed EBV-negative Hodgkin lymphoma by targeting upregulated MAGE-A4. Clin Cancer Res 17: 7058-7066, 2011.

33. Segura E and Villadangos JA: Antigen presentation by dendritic cells in vivo. Curr Opin Immunol 21: 105-110, 2009.

34. Willimsky G and Blankenstein T: Sporadic immunogenic tumours avoid destruction by inducing T-cell tolerance. Nature 437: 141-146, 2005 .
35. Drake CG, Jaffee E and Pardoll DM: Mechanisms of immune evasion by tumors. Adv Immunol 90: 51-81, 2006.

36. Diaz-Montero CM, Salem ML, Nishimura MI, Garrett-Mayer E Cole DJ and Montero AJ: Increased circulating myeloid-derived suppressor cells correlate with clinical cancer stage, metastatic tumor burden and doxorubicin-cyclophosphamide chemotherapy. Cancer Immunol Immunother 58: 49-59, 2009.

37. Meyer C, Cagnon L, Costa-Nunes CM, Baumgaertner P, Montandon N, Leyvraz L, Michielin O, Romano E and Speiser DE: Frequencies of circulating MDSC correlate with clinical outcome of melanoma patients treated with ipilimumab. Cancer Immunol Immunother 63: 247-257, 2014.

38. Shen P, Wang A, He M, Wang $\mathrm{Q}$ and Zheng S: Increased circulating Lin(-/low) CD33(+) HLA-DR(-) myeloid-derived suppressor cells in hepatocellular carcinoma patients. Hepatol Res 44: 639-650, 2014.

39. Bianchi G, Borgonovo G, Pistoia V and Raffaghello L: Immunosuppressive cells and tumour microenvironment: Focus on mesenchymal stem cells and myeloid derived suppressor cells. Histol Histopathol 26: 941-951, 2011

40. Fujimura T, Mahnke K and Enk AH: Myeloid derived suppressor cells and their role in tolerance induction in cancer. J Dermatol Sci 59: 1-6, 2010.

41. Sevko A and Umansky V: Myeloid-derived suppressor cells interact with tumors in terms of myelopoiesis, tumorigenesis and immunosuppression: Thick as thieves. J Cancer 4: 3-11, 2013.

42. Umansky V and Sevko A: Tumor microenvironment and myeloid-derived suppressor cells. Cancer Microenviron 6: 169-177, 2013.

43. Jungbluth AA, Ely S, DiLiberto M, Niesvizky R, Williamson B, Frosina D, Chen YT, Bhardwaj N, Chen-Kiang S, Old LJ, et al: The cancer-testis antigens CT7 (MAGE-C1) and MAGE-A3/6 are commonly expressed in multiple myeloma and correlate with plasma-cell proliferation. Blood 106: 167-174, 2005.

44. Forghanifard MM, Gholamin M, Farshchian M, Moaven O, Memar B, Forghani MN, Dadkhah E, Naseh H, Moghbeli M, Raeisossadati R, et al: Cancer-testis gene expression profiling in esophageal squamous cell carcinoma: Identification of specific tumor marker and potential targets for immunotherapy. Cancer Biol Ther 12: 191-197, 2011.

45. Nagao T, Higashitsuji H, Nonoguchi K, Sakurai T, Dawson S, Mayer RJ, Itoh K and Fujita J: MAGE-A4 interacts with the liver oncoprotein gankyrin and suppresses its tumorigenic activity. J Biol Chem 278: 10668-10674, 2003.

46. Park JH, Kong GH and Lee SW: hMAGE-A1 overexpression reduces TNF-alpha cytotoxicity in ME-180 cells. Mol Cells 14: 122-129, 2002.

47. Iclozan C, Antonia S, Chiappori A, Chen DT and Gabrilovich D Therapeutic regulation of myeloid-derived suppressor cells and immune response to cancer vaccine in patients with extensive stage small cell lung cancer. Cancer Immunol Immunother 62: 909-918, 2013

48. Waight JD, Netherby C, Hensen ML, Miller A, Hu Q, Liu S, Bogner PN, Farren MR, Lee KP, Liu K, et al: Myeloid-derived suppressor cell development is regulated by a STAT/IRF-8 axis. J Clin Invest 123: 4464-4478, 2013. 